\title{
Effect Of Reward System, Work Environment, And Empowerment On Organizational Citizenship Behavior Through Employee Engagement In Coal Utility Unit Of PT. Petrochemical Gresik
}

\author{
Ben Manggar Imawan dan Qausya Faviandhani \\ Program Studi Manajemen, Fakultas Ekonomi dan Bisnis \\ Universitas Narotama Surabaya \\ Email Author: qausya@narotama.ac.id
}

\begin{abstract}
This study aims to explore the performance of PT Petrokimia Gresik Coal Utility Unit employees who have recently emerged issues regarding employee performance that seem to have decreased so that testing is needed to prove whether the employee's performance has decreased. Exploration of employee performance is carried out using quantitative research methods, with the analysis technique using Path Analysis. By distributing several questionnaires to 40 employees who work in the Coal Utility Unit, to find out the results of the analysis required several tests such as the Validity Test which states valid, because the correlation value of each question item is greater than its critical value and for the Reliability Test it reaches Cronbach numbers. alpha 0.892 and above 0.60 , it is declared reliable and trustworthy. With the results of the calculations that have been done, it can be seen that the contribution of the Reward System, Work Environment and Empowerment variables affects the Employee Engagement and Organizational Citizenship Behavior variables as a measuring factor for employee performance.
\end{abstract}

Keyword:

Path Analysis, Employee Performance, Quantitative, Influence

\section{Pendahuluan}

\subsection{Latar Belakang}

Didalam suatu perusahaan, potensi Sumber Daya manusia pada hakekatnya merupakan salah satu modal utama dan memegang peranan penting dalam mencapai tujuan perusahaan. Karena di era global seperti sekarang ini yang ditandai dengan perubahan-perubahan pesat pada kondisi perekonomian secara keseluruhan, hal ini menimbulkan suatu tuntutan yang harus dipenuhi oleh para pelaku ekonomi maupun industri. Perubahan yang terjadi tidak hanya pada lingkungan eksternal namun juga pada lingkungan internal. Perubahan eksternal yang terjadi harus diikuti oleh perubahan internal dari organisasi itu sendiri salah satunya yaitu sumber daya manusia.

Sumber daya manusia merupakan aset berharga yang dimiliki oleh suatu organisasi. Oleh karena itu sebuah perusahaan perlu untuk mengelola sumber daya manusia mereka sebaik mungkin. Untuk mencapai tujuan, organisasi menuntut setiap karyawan melakukan pekerjaan secara efektif dan efisien. Hampir setiap organisasi diseluruh dunia telah bergeser dari bekerja secara individual menjadi bekerja dalam tim (Work Teams). Efektivitas dan kinerja tim tentunya ditentukan oleh kemampuan setiap individu untuk dapat saling berkomunikasi, jujur, mau bekerja sama, berbagi informasi, menghargai setiap perbedaan yang ada, mampu menyelesaikan konflik serta dapat mendahulukan kepentingan tim diatas kepentingan pribadi.

Kemampuan yang harus dimiliki oleh masing-masing individu yang bekerja dalam tim termasuk keterampilan interpersonal. Keterampilan tersebut dapat ditunjukkan oleh individu yang peduli terhadap individu lain yang berusaha menampilkan yang terbaik melebihi yang organisasi harapkan. Menurut Novliadi (2007: 7). Karena kunci sukses suatu perusahaan bukan hanya memiliki keunggulan teknologi tetapi faktor manusia sebagai faktor utama yang mampu mewujudkan tujuan perusahaan juga paling penting.

Menurut Hasibuan ( 2003, h 244 ) Pengertian Sumber daya Manusia adalah kemampuan terpadu dari daya pikir dan daya fisik yang dimiliki individu. Pelaku dan sifatnya dilakukan oleh keturunan dan lingkungannya, sedangkan prestasi kerjanya dimotivasi oleh keinginan untuk memenuhi kepuasannya.

SDM terdiri dari daya fikir dan daya fisik setiap manusia. Tegasnya kemampuan setiap manusia ditentukan oleh daya fikir dan daya fisiknya. SDM atau manusia menjadi unsur utama dalam setiap aktivitas yang dilakukan. Peralatan yang handal atau canggih tanpa peran aktif SDM, tidak berarti apa-apa. Daya pikir adalah kecerdasan yang dibawa sejak lahir ( modal dasar ) sedangkan kecakapan diperoleh dari usaha ( belajar dan pelatihan ). Kecerdasan tolak ukurnya Intelegence Quotient ( IQ ) dan Emotional Quality ( EQ ). 


\section{JURNAL EKONOMI}

Melalui perencanaan sumber daya manusia yang matang, produktivitas kerja dari tenaga kerja yang sudah ada dapat ditingkatkan. Namun apabila perencanaan tersebut kurang matang dapat mengakibatkan tujuan dari sebuah perusahaan dapat terganggu, terganggunya tujuan perusahaan ini juga dapat berdampak pada performance sebuah perusahaan, dan dampak tersebut juga memiliki hubungan terhadap kesejahteraan seluruh karyawan yang ada dalam perusahaan tersebut.

Sebagai salah satu produsen pupuk terbesar di asia tenggara tentunya PT. Petrokimia Gresik menginginkan potensi sumber daya manusia yang telah perusahaan seleksi untuk menjadi karyawan yang dapat memberikan hasil maksimal dan seirama dengan misi perusahaan yaitu "' Mendukung penyediaan pupuk nasional untuk tercapainya program swasembada pangan. Meningkatkan hasil usaha untuk menunjang kelancaran kegiatan operasional dan pengembangan usaha perusahaan. Mengembangkan potensi usaha untuk mendukung industri kimia nasional dan berperan aktif dalam community development'.

PT Petrokimia Gresik merupakan produsen pupuk di Indonesia, yang pada awal berdirinya disebut Proyek Petrokimia Surabaya (1962).

Kontrak pembangunannya ditandatangani pada tanggal 10 Agustus 1964, dan mulai berlaku pada tanggal 8 Desember 1964. Proyek ini diresmikan oleh Presiden Soeharto pada tanggal 10 Juli 1972, yang kemudian tanggal tersebut ditetapkan sebagai hari jadi PT Petrokimia Gresik.

Dalam perjalannya, PT Petrokimia Gresik telah mengalami sejumlah perubahan status, diantaranya adalah sebagai Perusahaan Umum (Perum) berdasarkan PP No. 55/1971, lalu berubah menjadi Persero berdasarkan PP No. 35/1974 jo PP No. 14/1975, dan sekarang sebagai anggota Holding PT Pupuk Indonesia (dahulu PT Pupuk Sriwidjaja) berdasarkan PP No. 28/1997.

PT Petrokimia Gresik menempati lahan seluas 450 hektare yang berlokasi di Kabupaten Gresik, Provinsi Jawa Timur. Pada tahun 2012 ini, PT Petrokimia Gresik dipercaya oleh pemerintah untuk meningkatkan kapasitas produksi menjadi 5,4 juta ton, atau meningkat 1,6 juta ton dibandingkan tahun 2011. Hal ini menjadikan PT Petrokimia Gresik sebagai produsen pupuk yang memasok 50\% kebutuhan pupuk subsidi nasional.

Dalam beberapa tahun terakhir ini muncul isu-isu yang dapat mempengaruhi kinerja karyawan di perusahaan, sebagian isu tersebut menyebabkan kinerja karyawan menurun.

Hal ini dapat dilihat dari fenomena yang ada pada unit kerja Utilitas Batu Bara PT Petrokimia Gresik melalui absensi karyawan yang menunjukan gejala-gejala melemah terhadap tugas yang telah menjadi tanggung jawabnya.

Tabel Grafik 1.1 Absensi Karyawan Utilitas Batubara Tahun 2015

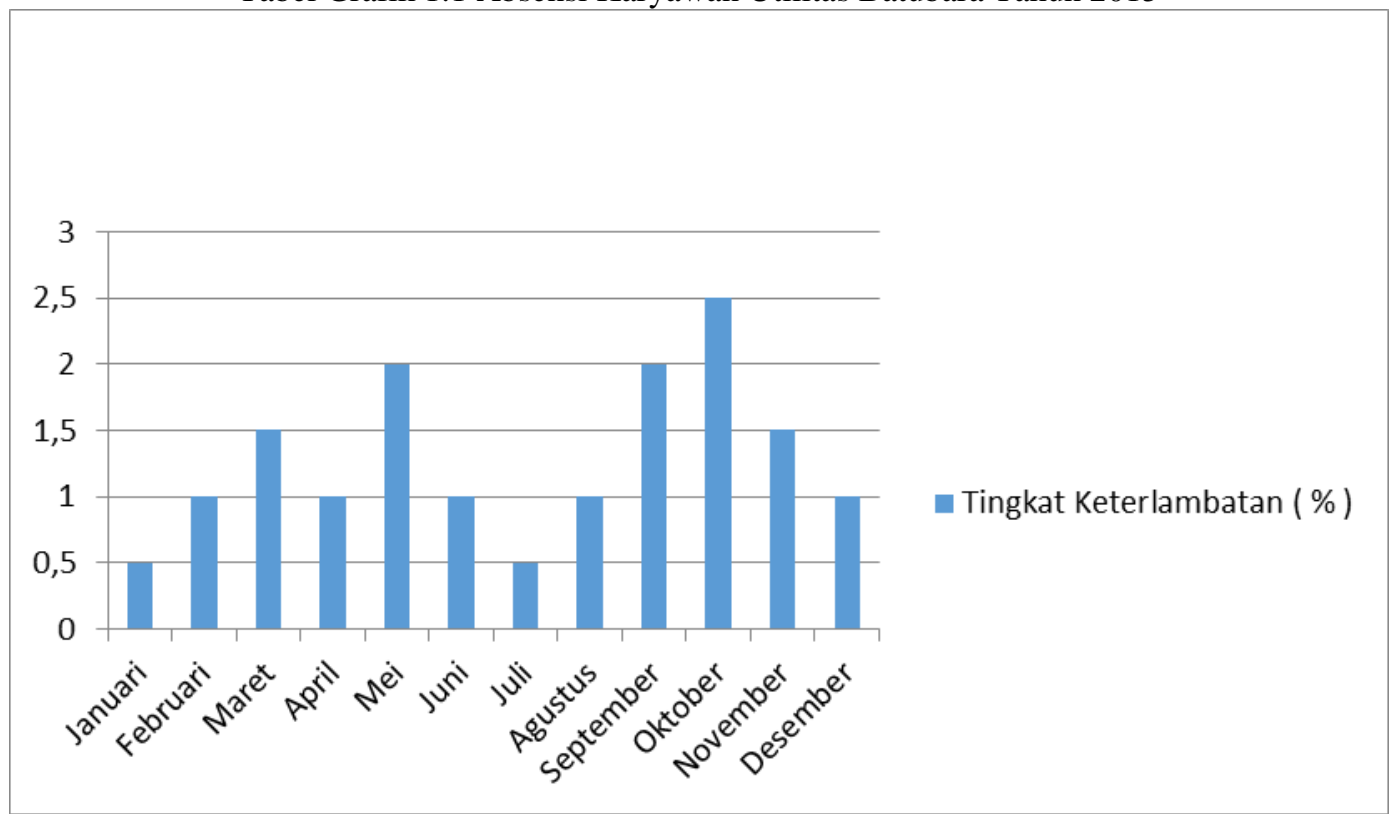

Mengingat suatu perusahaan yang mempekerjakan sumber daya manusia menginginkan suatu hasil dan manfaat yang baik dan dapat mengikuti perkembangan yang terjadi dalam perusahaan, maka diperlukan keterikatan antara karyawan terhadap pekerjaan yang menjadi tanggung jawabnya.

Keterikatakan atau Employee engagement merupakan rasa keterikatan secara emosional dengan pekerjaan dan organisasi, termotivasi dan mampu memberikan kemampuan terbaik mereka untuk membantu sukses dari serangkaian manfaat nyata bagi organisasi dan individu, (McLeod, 2009)

Dalam menimbulkan rasa keterikatan di pengaruhi beberapa hal seperti sistem reward, work environment, dan empowerement, unsur - unsur pendukung inilah yang dapat dijadikan pertimbangan seorang karyawan sehingga muncul rasa employee engagement. 


\section{JURNAL EKONOMI}

Sistem reward ( Kompensasi ) Menurut Mulyadi dan Setyawan (2001:227) sistem penghargaan merupakan salah satu alat pengendali penting yang digunakan oleh perusahaan untuk memotivasi personelnya agar mencapai tujuan perusahaan (bukan tujuan personel secara individu) dengan perilaku sesuai dengan yang diharapkan oleh perusahaan (bukan perilaku yang disukai oleh personel secara pribadi).

Work Environment ( Lingkungan Kerja ) Menurut Nitisemito (2001:183) mengemukakan bahwa:

"Lingkungan kerja adalah segala sesuatu yang ada disekitar para pekerja yang dapat mempengaruhi dirinya dalam menjalankan tugas-tugas yang dibebankan. Misalnya kebersihan, musik dan lain-lain".

Empowerment ( Pemberdayaan ) Menurut Prijono dan Pranarka, (1996 : 3) mengandung dua pengertian yaitu : pengertian pertama adalah to give power or authority to, dan pengertian kedua berarti to give ability to or enable. dalam pengertian pertama diartikan sebagai memberi kekuasaan, mengalihkan kekuatan atau mendelegasikan otoritas ke pihak lain. sedang dalam pengertian kedua, diartikan sebagai upaya untuk memberikan kemampuan atau keberdayaan.

Dalam melakukan usaha meningkatkan produktivitas kerja ini, PT Petrokimia Gresik telah mengupayakan beberapa faktor agar dapat menunjang tujuan tersebut, salah satunya adalah dengan sistem reward, memperhatikan work environment serta empowerment atau pemberdayaan.

Berdasarkan uraian diatas, menjelaskan tentang hubungan keterikatan terhadap kinerja karyawan, maka penulis tertarik untuk melakuakn penelitian dengan mengambil judul: "Pengaruh sistem reward, work environment dan empowerment terhadap organizational citizen behavior melalui employee engagement pada unit Utilitas Batu Bara PT. Petrokimia Gresik “.

\subsection{Perumusan Masalah}

Berdasarkan uraian latar belakang masalah diatas maka pokok masalah yang dihadapi dalam penelitian ini di uraikan sebagai berikut ini

1. Apakah sistem reward berpengaruh signifikan terhadap employee engagement?

2. Apakah work environment berpengaruh signifikan terhadap employee engagement?

3. Apakah empowerment berpengaruh signifikan terhadap employee engagement?

4. Apakah sistem reward berpengaruh signifikan terhadap organizational citizen behavior?

5. Apakah work environment berpengaruh signifikan terhadap organizational citizen behavior?

6. Apakah empowerment berpengaruh signifikan terhadap organizational citizen behavior?

7. Apakah sistem reward, work environment, empowerment berpengaruh signifikan terhadap organizational citizen behavior melalui variabel employee engangement?

\section{Tinjauan Pustaka}

\subsection{Penelitian Terdahulu}

Linda Kartini Ticoalu, 2013 Tujuan melakukan penelitian ini adalah untuk mengetahui bagaimana pengaruh organizational citizenship behavior (OCB) dan komitmen organisasi terhadap kinerja karyawan. Metode yang digunakan dalam penelitian ini adalah penelitian asosiatif. Populasi yang digunakan adalah seluruh pegawai atau karyawan pada PT. Bank Tabungan Pensiunan Nasional yang berjumlah 50 orang. Alat analisis yang digunakan adalah regresi linier berganda. Hasil penelitiannya menunjukan bahwa organizational citizenship behavior (OCB) dan komitmen organisasi berpengaruh terhadap kinerja karyawan.

Dian Ismaya, 2014 Penelitian ini mempunyai tujuan untuk menguji pengaruh kepemimpinan transformasional dan keadilan prosedural pada komitmen organisasi dan perilaku warga organisasi. Selain itu, penilitian ini juga bertujuan untuk menyelidiki peran komitmen organisasi sebagai variabel intervening pada hubungan kepimpinan transformasional, keadilan prosedural dan OCB. Populasi yang digunakan penelitian ini adalah 139 perawat dengan sampel 128 perawat. Metode survei yang digunaka dalam penelitian ini untuk mendapatkan data adalah dengan menggunakan kuisioner. Teknik analisis data yang digunakan penelitian ini untuk menguji hipotesis regresi sederhana, regresi berganda, regresi bertingkat. Hasil penelitian ini mengemukakan bahwa kepemimpinan transformasional, komitmen prosedural dan organisasi memiliki efek siginifikan terhadap perilaku warga organisasi.

Wustari L.H Mangundjaya, 2012 penelitian ini bertujuan untuk mengetahui hubungan dan pengaruh persepsi terhadap dukungan organisasi dan kepuasaan kerja terhadap PKO. Penelitian ini digunakan pada karyawan yang bekerja di lembaga keuangan ( $\mathrm{N}=203$ ), dengan menggunakan 3 jenis skala, pengumpulan data yaitu Persepsi Dukungan Organisasi ( POS ), Kepuasan Kerja, dan Perilaku Kewarganegaraan Organisasi ( PKO ). Analisis yang dilakukan adalah dengan menggunakan korelasi berganda. Dari peneiltian yang dilakukan diperoleh hasil yang menunjukan adanya pengaruh yang positif dan signifikan dari kepuasan kerja terhadap PKO ( $\mathrm{r}=0,19 ; \mathrm{p}, 0,01$ ), dan tidak terdapat pengaruh yang signifikan antara persepsi terhadap Dukungan Organisasi pada PKO ( $r=0,05 ; \mathrm{p}>0,05$ ). Berdasarkan hasil tersebut, tampak bahwa kepuasan kerja merupakan prediktor dan memiliki peran yang lebih penting terhadap PKO dibandingkan dengan persepsi terhadap dukungan organisasi. 
Lutfianita Novira,2015 penelitian ini bertujuan untuk mengetahui adanya pengaruh mediasi kepuasan kerja antara variabel persepsi dengan dukungan organisasi terhadap PKO, populasi yang di gunakan dalam penelitian ini adalah pegawai kantor Perum Perhutani Unit I Jawa Tengah, teknik pengambilan data yang digunakan adalah proportionale random sampling dan jumlah perhitungan menggunakan rumus slovin sebanyak 116 orang. Menggunakan metode pengumpulan data kuisioner, dengan metode analisis menggunakan uji parsial dan analisis sobel dalam menentukan hubungan antar variabel dengan menggunakan SPSS. Hasil penelitian mengemukakan bahwa terdapat pengaruh positif dan signifikan antara variabel persepsi dukungan organisasi tehadap kepuasan kerja. Kesimpulan penelitian ini adalah persepsi dukungan organisasi dan kepuasan kerja sangat berperan penting dalam timbulnya PKO.

\section{Metode Penelitian}

\subsection{Pendekatan Penelitian}

Pendekatan dalam penelitian ini adalah pendekatan kuantitatif, karena penelitian ini disajikan dengan angka-angka. Hal ini sesuai dengan pendapat ( Arikunto 2006: 12 ) yang mengemukakan penelitian kuantitatif adalah pendekatan penelitian yang banyak dituntut menggunakan angka, mulai dari pengumpulan data, penafsiran terhadap data tersebut, serta penampilan hasilnya

\subsection{Populasi dan Sampel}

1. Populasi Penelitian

Menurut Arikunto (2006: 130) populasi adalah keseluruhan subjek penelitian. Populasi dalam penelitian ini adalah seluruh karyawan yang bekerja di unit utilitas batubara PT Petrokimia Gresik yang berjumlah 40 orang.

2. Sampel Penelitian

Menurut Arikunto (206: 131) sampel adalah sebagian atau wakil dari jumlah populasi yang diteliti. Sampel penelitian yang digunakan adalah sampel bertujuan atau purposive sample. Sampel bertujuan dilakukan dengan cara mengambil subjek bukan didasarkan atas strata, random, atau daerah tetapi didasarkan atas adanya tujuan tertentu. Jadi penelitian ini menggunakan purposive sample karena di yakini sample yang akan di ambil mencakup keseluruhan sampel yang ada pada unit utilitas Batu Bara pada PT. Petrokimia Gresik. Sehubungan subjek kurang dari 100, maka cara untuk menentukan sampel adalah sebagai berikut:

a. Kemampuan peneliti dilihat dari waktu, tenaga,dan dana.

b. Sempit luasnya wilayah pengamatan dari setiap subjek, karena hal ini menyangkut banyaknya data.

c. Besar kecilnya risiko yang ditanggung oleh peneliti.

\subsection{Jenis, Sumber dan Teknik Pengumpulan Data}

Data primer yaitu data yang diambil secara langsung dari objek / obyek penelitian oleh peneliti perorangan ataupun organisasi.

Pada penelitian kali ini peneliti menggunakan jenis penelitian kuantitatif, terdapat tiga pengumpulan data berdasarkan tekniknya yaitu wawancara,angket ( kuisioner ), dan Observasi ( Sugiyono 2013:194 ).

Sumber data yang di peroleh adalah langsung dari internal perusahaan,yaitu sumber data yang memperlihatkan situasi dan kondisi pada suatu perusahaan atau organisasi secara internal, dengan populasi 40 orang yang berstatus karyawan unit utilitas batubara sebagai sumber pengamatan.

Teknik pengambilan data dengan interview ( wawancara ), angket ( kuisioner ), dan observasi.

\section{Hasil Penelitian Dan Pembahasan}

Beberapa pengaruh parsial ( langsung dan tidak langsung melalui Y1 (Employee Engangement) dan pengaruh stimultan X1 ( Sistem Reward), X2 ( Work Environment ) dan X3 ( Empowerment) terhadap Y1 ( Employee Engagement ) dan Z1 ( Organizational Citizenship Behavior ) di uraikan sebagai berikut :

\section{1 Pembahasan Pengaruh Parsial ( Pengaruh Langsung ) Model 1}

1. Pengaruh Parsial Sistem Reward terhadap Employee Engangement

Kontribusi Sistem Reward secara langsung terhadap Employee Engangement sebesar ( 0,051 $) 2=0,002$ atau sebesar $0,2 \%$. Nilai $t$ hitung $0,309<$ nilai $t$ tabel 1,679 dengan tingkat signifikansi sebesar 0,759 > 0,05, artinya Sistem Reward tidak berpengaruh dan tidak signifikan terhadap Employee Engangement.

2. Pengaruh Parsial Work Environment terhadap Employee Engangement

Kontribusi Work Environment secara langsung terhadap Employee Engangement sebesar $(0,140) 2=0,019$ atau sebesar 1,9\%. Nilai t hitung 0,695 < nilai t tabel 1,679 dengan tingkat signifikansi sebesar 0,492 >0,05, artinya Work Environment tidak berpengaruh dan tidak signifikan terhadap Employee Engangement.

3. Pengaruh Parsial Empowerment terhadap Employee Engangement 
Kontribusi Empowerment secara langsung terhadap Employee Engangement sebesar ( 0,576 $) 2=0,331$ atau sebesar 33,1\%. Nilai t hitung 3,586 > nilai t tabel 1,679 dengan tingkat signifikansi sebesar 0,001< 0,05, artinya Empowerment berpengaruh secara signifikan terhadap Employee Engangement.

Dari perhitungan di atas, terlihat bahwa Empowerment memiliki kontribusi tertinggi terhadap Employee Engangement dengan nilai sebesar 0,331 atau $33,1 \%$.

\section{2 Pembahasan Pengaruh Parsial ( Pengaruh Langsung ) Model 2}

1. Pengaruh Parsial Sistem Reward terhadap Organizational Citizenship Behavior Kontribusi Sistem Reward secara langsung terhadap Organizational Citizenship Behavior sebesar ( 0,126 )2 $=0,015$ atau sebesar $1,5 \%$. Nilai t hitung $0,939<$ nilai t tabel 1,679 dengan tingkat signifikansi sebesar 0,354 > sig. 0.05, artinya Sistem Reward tidak signifikan terhadap Organizational Citizenship Behavior.

2. Pengaruh Parsial Work Environment terhadap Organizational Citizenship Behavior Kontribusi Sistem Reward secara langsung terhadap Organizational Citizenship Behavior sebesar ( 0,233 )2 $=0,054$ atau sebesar 5,4\%. Nilai t hitung 1,430 < nilai t tabel 1,679 dengan tingkat signifikansi sebesar 0,162 > sig. 0,05, artinya Work Environment tidak signifikan terhadap Organizational Citizenship Behavior.

3. Pengaruh Parsial Empowerment terhadap Organizational Citizenship Behavior

Kontribusi Empowerment secara langsung terhadap Organizational Citizenship Behavior sebesar ( 0,253 )2 $=0,064$ atau sebesar 6,4\%. Nilai t hitung 1,683 > nilai t tabel 1,679 dengan tingkat signifikansi sebesar 0,101 > sig. 0,05, artinya Empowerment masih tidak signifikan meskipun nilai $\mathrm{t}$ hitung $>$ dari t tabel terhadap Organizational Citizenship Behavior.

Dari perhitungan di atas, terlihat bahwa Empowerment memiliki kontribusi tertinggi terhadap Organizational Citizenship Behavior dengan nilai 0,064 atau sebesar 6,4\%.

\subsection{Pengaruh Parsial ( tidak langsung ) dari model 1 dan 2}

1. Pengaruh Parsial Sistem Reward terhadap Organizational Citizenship Behavior melalui Employee Engangement

$=0,126+(0,051 \times 0,369)$

$=0,126+0,018$

$=0,144$

Besarnya pengaruh tidak langsung Sistem reward terhadap Organizational Citizenship Behavior melalui Employee Engangement adalah 0,144 atau sebesar 14,4\%. Sisanya sebesar 114,4\% dipengaruhi oleh variabel Work Environment dan Empowerment.

2. Pengaruh Parsial Work Environment terhadap Organizational Citizenship Behavior melalui Employee Engangement

$=0,233+(0,140 \times 0,369)$

$=0,233+0,051$

$=0,284$

Besarnya pengaruh tidak langsung Work Environment terhadap Organizational Citizenship Behavior melalui Employee Engangement adalah 0,284 atau sebesar 28,4\%. Sisanya sebesar 112,8\% dipengaruhi oleh variabel Sistem Reward dan Empowerment.

3. Pengaaruh Parsial Empowerment terhadap Organizational Citizenship Behavior melalui Employee Engangement.

$=0,253+(0,576 \times 0,369)$

$=0,253+0,212$

$=0,465$

Besarnya pengaruh tidak langsung Empowerment terhadap Organizational Citizenship Behavior melalui Employee Engangement adalah 0,465 atau sebesar 46,5\%. Sisanya sebesar 146,5\% dipengaruhi oleh Sistem Reward dan Work Environment.

\section{4 Pembahasan Pengaruh Simultan Model 1}

Kontribusi X1 ( Sistem Reward ), X2 ( Work Environment ) dan X3 ( Empowerment ) secara simultan yang langsung mempengaruhi Y1 (Employee Engangement ) sebesar R2 square yaitu 0,500 atau 50\%, sisanya sebesar 50\% di pengaruhi faktor - faktor lain yang tidak dapat di jelaskan dalam penelitian ini. Hasil uji $\mathrm{F}$ didapatkan nilai $\mathrm{F}=11,988$ dengan sig. 0,000 sehingga kelayakan model ini dapat diterima.

\subsection{Pembahasan Pengaruh Simultan Model 2}

Kontribusi X1 ( Sistem Reward ), X2 ( Work Environment ) dan X3 ( Empowerment ) secara simultan yang langsung mempengaruhi Z1 (Organizational Citizenship Behavior ) sebesar R2 square yaitu 0,686 atau $68,6 \%$, sisanya sebesar $31,4 \%$ di pengaruhi faktor - faktor lain yang tidak dapat dijelaskan dalam penelitian ini. Hasil uji $\mathrm{F}$ di dapatkan nilai $\mathrm{F}=19,078$ dengan sig. 0,000 sehingga kelayakan model ini dapat diterima. 


\section{6 Rangkuman Dekomposisi Path Analysis Model Struktur 1 dan 2}

Besarnya pengaruh parsial ( langsung dan tidak langsung ) dan simultan variabel X1, X2, X3, terhadap Y1 dan Z1 dapat dituangkan dalam tabel 1 sebagai berikut :

Tabel 1. Rangkuman Dekomposisi Pengaruh Parsial dan Simultan Sistem Reward (X1), Work Environment (X2), Empowerment (X3), Terhadap Employee Engangement ( Y1) dan Organizational Citizenship Behavior ( Z1 )

\begin{tabular}{|c|c|c|c|c|}
\hline & Pengaruh & Kausal & & \\
\hline Pengaruh Variabel & Langsung & $\begin{array}{l}\text { Tidak Langsung } \\
\text { (melalui } Y_{1)}\end{array}$ & $\begin{array}{c}\text { Sisa } \\
\left(\mathrm{e}_{1} \text { dan } \mathrm{e}_{2}\right)\end{array}$ & Total \\
\hline $\mathrm{X}_{1}$ terhadap $\mathrm{Y}_{1}$ & 0,051 & $0126+(0051 \times 0369)$ & & 0,051 \\
\hline $\mathrm{X}_{2}$ terhadap $\mathrm{Y}_{1}$ & 0,140 & & & 0,140 \\
\hline $\mathrm{X}_{3}$ terhadap $\mathrm{Y}_{1}$ & 0,576 & $\begin{array}{l}0,233+(0,140 \times 0,369) \\
0,253+(0,576 \times 0,369)\end{array}$ & & $\begin{array}{l}0,284 \\
0,576 \\
0,465\end{array}$ \\
\hline $\mathrm{X}_{1}, \mathrm{X}_{2}, \mathrm{X}_{3}$, terhadap $\mathrm{Y}_{1}$ & 0,500 & & 0,500 & 1 \\
\hline $\begin{array}{c}\mathrm{X}_{1} \text { terhadap } \mathrm{Z}_{1} \\
\mathrm{X}_{2} \text { terhadap } \mathrm{Z}_{1} \\
\mathrm{X}_{3} \text { terhadap } \mathrm{Z}_{1} \\
\mathrm{X}_{1} \mathrm{X}_{2}, \mathrm{X}_{3} \text {, terhadap } \mathrm{Z}_{1}\end{array}$ & $\begin{array}{l}0,126 \\
0,233 \\
0,253 \\
0,686\end{array}$ & & 0,314 & $\begin{array}{c}0,126 \\
0,233 \\
0,253 \\
1\end{array}$ \\
\hline
\end{tabular}

\section{Penutup}

\subsection{Kesimpulan}

Penelitian ini mencoba untuk menjawab pengaruh parsial ( langsung / tidak langsung ) dan simultan Sistem Reward, Work Environment dan Empowerment terhadap Employee Engangement dan Organizational Citizenship Behavior pada Unit Utilitas Batu Bara PT. Petrokimia Gresik tahun 2016. Pembahasan hasil penelitian menggunakan path analysis menunjukan bahwa :

1. Variabel Sistem Reward secara parsial tidak berpengaruh dan tidak signifikan terhadap Employee Engangement pada Unit Utilitas Batu Bara yang dijadikan sampel penelitian. Kontribusi langsung Sistem Reward terhadap Employee Engangement adalah sebesar 0,2 \%.

2. Variabel Work Environment secara parsial tidak berpengaruh dan tidak signifikan terhadap Employee Engangement pada Unit Utilitas Batu Bara yang dijadikan sampel penelitian. Kontribusi langsung Work Environment terhadap Employee Engangement adalah sebesar 1,9\%.

3. Variabel Empowerment secara parsial berpengaruh dan signifikan terhadap Employee Engangement pada Unit Utilitas Batu Bara yang dijadikan sampel penelitian. Kontribusi langsung Empowerment terhadap Employee Engangement adalah sebesar 33,1\%.

4. Variabel Sistem Reward secara parsial tidak berpengaruh dan tidak signifikan terhadap Organizational Citizenship Behavior pada Unit Utilitas Batu Bara yang dijadikan sampel penelitian. Kontribusi langsung Sistem Reward terhadap Organizational Citizenship Behavior sebesar 1,5\%.

5. Variabel Work Environment secara parsial berpengaruh dan signifikan terhadap Organizational Citizenship Behavior pada Unit Utilitas Batu Bara yang dijadikan sampel penelitian. Kontribusi langsung Work Environment terhadap Organizational Citizenship Behavior sebesar 5,4 \%.

6. Variabel Empowerment secara parsial berpengaruh dan signifikan terhadap Organizational Citizenship Behavior pada Unit Utilitas Batu Bara yang dijadikan sampel penelitian. Kontribusi langsung Empowerment terhadap Organizational Citizenship Behavior sebesar 6,4 \%.

7. Kontribusi tidak langsung Sistem Reward terhadap Organizational Citizenship Behavior melalui Employee Engangement adalah sebesar $14,4 \%$.

8. Kontribusi tidak langsung Work Environment terhadap Organizational Citizenship Behavior melalui Employee Engangement adalah sebesar $28,4 \%$.

9. Kontribusi tidak langsung Empowerment terhadap Organizational Citizenship Behavior melalui Employee Engangement adalah sebesar $46,5 \%$.

10. Kontribusi Sistem Reward, Work Environment dan Empowerment secara simultan yang langsung mempengaruhi Employee Engangement sebesar 50\%, sisanya sebesar $50 \%$ dipengaruhi oleh faktor faktor yang tidak dapat dijelaskan dalam penelitian ini. 
11. Kontribusi Sistem Reward, Work Environment dan Empowerment secara simultan yang langsung mempengaruhi Organizational Citizenship Behavior sebesar 68,6 \%, sisanya sebesar 31,4 \% dipengaruhi oleh faktor - faktor yang tidak dapat dijelaskan dalam penelitian ini.

\subsection{Saran}

Berdasarkan simpulan dari hasil penelitian yang telah disampaikan di atas, maka saran yang dapat diberikan oleh peneliti adalah sebagai berikut :

1. Bagi perusahaan hendaknya lebih menjaga dan menstabilkan rasio Empowerment di posisi ideal agar terciptanya kestabilan dalam melakukan pekerjaan di dalam Unit Utilitas Batu Bara sehingga Employee Engangement dan Organizational Citizenship Behavior bisa meningkat.

2. Bagi peneliti selanjutnya diharapkan dapat menambah variabel independen yang lain di luar variabel Sistem Reward, Work Environment dan Empowerment agar memperoleh hasil yang lebih bervariasi dan dapat menggambarkan apa saja yang bisa mempengaruhi Employee Engangement dan Organizational Citizenship Behavior.

\section{Daftar Pustaka}

Alex, S., Nitisemito, 2001. Manajemen Personalia, Jakarta : Ghalia Indonesia

A. M. W. Pranarka dan Vidhandika Moeljarto, "Pemberdayaan (Empowerment)", dalam Onny S. Prijono dan A.M.W Pranarka (eds), 1996. Pemberdayaan :

Konsep, Kebijakan dan Implementasi, CSIS, Jakarta, hal.44-46

Arikunto S, 2006. Prosedur Penelitian Suatu Pendekatan Praktik, Ed Revisi VI,

Penerbit PT Rineka Cipta, Jakarta

Bathla Shalu. Periodontics Revisited. India: Jaypee Brother Medical Publishers. 2011

Byars \& Rue, 2000, Human Resources Management, Fifth Edition. New York: McGraw-

Hill, Inc.

Dicke, C., Holwerda, J., \& Kontakos, A. (2007). Employee engagement: What do we

really know? What do we need to know to take action?. Paris: Marriot Paris

Champs-Elyses

DR. Riduwan, M.B.A. 2010, Cara Menggunakan Path Analysis, Bandung : Alfabeta

Ghozali, I 2005. Multivariate dengan program SPSS Semarang : Badan Penerbit Universitas Diponegoro

Harter, J. K., Schmidt, F. L., \& Hayes, T. L. (2002). Business-unit-level relationship between employee satisfaction, employee engagement, and business outcomes: a meta-analysis. Journal Of Applied Psychology , 87 (2), 268-279.

Hasibuan, Malayu, S.P. 2003. Manajemen Dasar, Pengertian dan

Masalah. Jakarta : PT Toko Gunung Agung

Joreskog, K.G. \& Dag Sorbom. (1993). LISREL 8 : Structural Equation Modeling with the Simplis Comand Language. Chicago : Scientific Software International. Inc

Maruyama, Geoffey M. (1998). Basic of Structural Equation Modeling. USA : Sage Publications. Inc.

Markos, S., \& Sridevi, M.S. (2010). Employee Engagement: The Key to

Improving Performance. International Journal of Bussiness and

Management. 5(12), 89-96.

Mulyadi, John S, 2001. Sistem Perencanaan Pengendalian Management. Penerbit Salemba 4, edisi 2.

Novliadi, Ferry. (2007). Intensi Turnover Karyawan Ditinjau Dari Budaya Perusahaan Dan Kepuasan Kerja. ( Online ). Tersedia ( 4 November 2008 )

Organ, D. W. 1988. Organizational citizenship behavior: The good soldier syndrome. Lexington, MA: Lexington Books.

Prof. DR. Ratlan Pardede Analisis jalur, Jakarta : Rineka Cipta Schaufeli, W.B., Bakker, A.B. (2003). UWES Utrecht Work Engagement Scale Preliminary Manual. Occupational Health Psychology Unit Utrech University. Sugiyono. 2009, Metode Penelitian Administrasi, Bandung : Alfabeta

Kurnianingsih, R, dan Indriantoro, Nur, 2001, Pengaruh Sistem Pengukuran Kinerja dan Sistem Penghargaan terhadap keefektifan TQM (Study Empiris pada Perusahaan Manufaktur di Indonesia), Jurnal Riset Akuntansi Indonesia hal 28. 